\begin{tabular}{|c|c|}
\hline Title & Combustion synthesis of Y A G:Ce phosphors via the thermite reaction of aluminum \\
\hline Author(s) & Ohyama, Junpei; Zhu, Chunyu; Saito, Genki; Haga, Miki; Nomura, Takahiro; Sakaguchi, Norihito; A kiy ama, Tomohiro \\
\hline Citation & $\begin{array}{l}\text { Journal of rare earths, } 36(3), 248-256 \\
\text { https://doi .org/10.1016/.jre.2017.06.014 }\end{array}$ \\
\hline Issue Date & $2018-03$ \\
\hline DOC URL & http:/hdl.handle.net/2115/76824 \\
\hline Rights & $\begin{array}{l}\text { O2018. This manuscript version is made available under the CC-BY-NC-ND } 4.0 \text { license } \\
\text { http://reativecommons.org/icenses/by-nc-nd/4.0/ }\end{array}$ \\
\hline Rights(URL) & https://creativecommons.org/icenses/by-nc-nd/4.0/ \\
\hline Type & article (author version) \\
\hline File Information & YAG revised v17.pdf \\
\hline
\end{tabular}

Instructions for use 


\title{
Combustion synthesis of YAG:Ce phosphors via the thermite reaction
}

\section{of aluminum}

Junpei Ohyama ${ }^{a}$, Chunyu Zhu ${ }^{b, c}$, Genki Saito $^{a^{*}}$, Haga Miki $^{a}$, Takahiro Nomura ${ }^{a}$, Norihito Sakaguchi ${ }^{a}$, and Tomohiro Akiyama ${ }^{a}$

${ }^{a}$ Center for Advanced Research of Energy and Materials, Hokkaido University, Kita 13 Nishi 8, Kitaku, Sapporo 060-8628, Japan

${ }^{b}$ Division of Applied Chemistry \& Frontier Chemistry Center, Faculty of Engineering, Hokkaido University, Sapporo, Hokkaido 060-8628, Japan

${ }^{c}$ Graduate School of Chemical Sciences and Engineering, Hokkaido University, Sapporo, Hokkaido 060-8628, Japan

\begin{abstract}
Cerium-doped yttrium aluminum garnet (YAG:Ce) as a yellow phosphor for white light-emitting diodes (LEDs) was synthesized via a facile combustion method using $\mathrm{Y}_{2} \mathrm{O}_{3}, \mathrm{CeO}_{2}, \mathrm{Al}_{2} \mathrm{O}_{3}, \mathrm{Al}$, and $\mathrm{NaClO}_{4}$ as raw materials. The combustion synthesis approach utilizes the strong exothermic oxidation of aluminum to realize a self-sustaining reaction. In this study, we investigated the effects of the ratios of $\mathrm{Al}_{2} \mathrm{O}_{3}$ to $\mathrm{Al}$, fluxes, and coprecipitated materials as raw materials on the luminescence properties of the synthesized YAG:Ce phosphors. When the amount of $\mathrm{Al}_{2} \mathrm{O}_{3} \mathrm{x}$ was varied, the combustion reaction proceeded at $\mathrm{x} \leq 1.8$, with $\mathrm{x}=1.725$ being the optimum condition for producing a high-performance product. When 5 mass $\% \mathrm{BaF}_{2}$ was added, the luminescence intensity was significantly improved owing to a decrease of $\mathrm{YAP}\left(\mathrm{YAlO}_{3}\right)$ formation with improved uniformity. However, the addition of $\mathrm{CaF}_{2}$ and $\mathrm{NaF}$ did not improve the luminescence properties. To suppress the segregation of $\mathrm{CeO}_{2}$, we used the coprecipitated material $\mathrm{Y}_{2} \mathrm{O}_{3}-\mathrm{CeO}_{2}$ as a raw material. Unlike with separate addition of $\mathrm{Y}_{2} \mathrm{O}_{3}$ and $\mathrm{CeO}_{2}$, Ce ions were uniformly distributed in the coprecipitated material, resulting in improved luminescence properties. The combination of $\mathrm{BaF}_{2}$ and coprecipitated material significantly improved the internal quantum efficiency to $83.0 \%$, which is close to that of commercial phosphors.
\end{abstract}

Keywords: phosphor, yttrium aluminum garnet, combustion synthesis, flux, coprecipitated material

* Corresponding author: GENKI Saito (E-mail: genki@eng.hokudai.ac.jp; Tel.:

+81-11-706-6766) 


\section{Introduction}

Ce-doped $\mathrm{Y}_{3} \mathrm{Al}_{5} \mathrm{O}_{12}$ (YAG:Ce) phosphors have been widely used as yellow phosphors for white light-emitting diodes (LEDs) owing to their high emission efficiency under blue light excitation. In conventional solid-state reactions, the synthesis of pure YAG:Ce phosphors requires high-temperature (> $1500{ }^{\circ} \mathrm{C}$ ) treatment, which is both energy- and time-consuming. Therefore, lower temperature syntheses, such as spray pyrolysis[1], sol-gel processing[2-4], coprecipitation method[5, 6], citrate sol-gel combustion preparation[7-10], and hydrothermal synthesis[11], have been proposed. However, these processes require the use of nitrates, such as $\mathrm{Al}\left(\mathrm{NO}_{3}\right)_{3}$ and $\mathrm{Y}\left(\mathrm{NO}_{3}\right)_{3}$, which still necessitate the use of high temperature treatments. To resolve this problem, this paper proposes a combustion synthesis (self-propagation high-temperature synthesis) of YAG:Ce phosphor using aluminum oxidation heat. Combustion synthesis using the thermite reaction of Al employs the propagation of a strong exothermic reaction, namely, $\mathrm{Al}$ oxidation, which is a self-sustaining reaction. This method has advantages of low energy consumption and short reaction times, and has been applied to produce a variety of advanced materials, such as oxides[12-14], nitride/oxynitride ceramics[15-17], and intermetallics[18, 19].

In this study, we examined the facile and effective combustion synthesis of YAG:Ce phosphors via the thermite reaction of $\mathrm{Al}$, where the oxidation heat of $\mathrm{Al}$ is used for self-propagation of the high-temperature synthesis. The key for successful combustion synthesis of YAG:Ce phosphors is regulating the reaction temperature, which can be optimized by controlling the ratio of $\mathrm{Al}$ and $\mathrm{Al}_{2} \mathrm{O}_{3}$ in 
the raw materials. We also investigated the effects of fluxes and coprecipitated materials on the luminescence properties of the synthesized YAG:Ce phosphors. It is known that flux addition greatly influences ion diffusion and crystallization processes, resulting in improved phase uniformity and luminescence properties $[1,20]$. For single crystalline YAG growth, fluxes such as $\mathrm{PbO}-\mathrm{PbF}_{2}$ and $\mathrm{PbO}-\mathrm{PbF}_{2}-\mathrm{B}_{2} \mathrm{O}_{3}$ have been used[21]. Among the various available fluxes, fluoride-type fluxes such as $\mathrm{BaF}_{2}, \mathrm{CaF}_{2}, \mathrm{MgF}_{2}$, and $\mathrm{AlF}_{3}$ have been found to be effective for aluminate-type phosphors [20, 22, 23]. However, the effect of these fluxes on combustion-synthesized phosphors is unknown. In addition, we studied the effect of utilizing coprecipitated $\mathrm{Y}_{2} \mathrm{O}_{3}-\mathrm{CeO}_{2}$ as a raw material. Because $\mathrm{Y}$ and Ce ions are uniformly distributed in the coprecipitated material, suppression of $\mathrm{CeO}_{2}$ segregation and increased uniformity are expected. 
2. Material and methods

YAG:Ce phosphors with a Ce ratio of 1.0 at\% were prepared from commercially available $\mathrm{Y}_{2} \mathrm{O}_{3}\left(99.99 \%\right.$ purity), $\mathrm{CeO}_{2}$ (99.99\% purity), $\mathrm{Al}_{2} \mathrm{O}_{3}$ (99.99\% purity), $\mathrm{Al}$ (99.99\% purity), and $\mathrm{NaClO}_{4}$ (98\% purity) powders. $\mathrm{Al}_{2} \mathrm{O}_{3}$ acts as a diluent to control the combustion flame temperature. The reaction formula for the combustion synthesis can be written as shown in Eq. 1 .

$1.485 \mathrm{Y}_{2} \mathrm{O}_{3}+0.03 \mathrm{CeO}_{2}+\mathrm{xAl}_{2} \mathrm{O}_{3}+(5-2 \mathrm{x}) \mathrm{Al}+\mathrm{yNaClO}_{4} \rightarrow \mathrm{Y}_{3} \mathrm{Al}_{5} \mathrm{O}_{12}+\mathrm{yNaCl}$ $(y=(7.485-3 x) / 4)$

Here, $x$ refers to the amount of $\mathrm{Al}_{2} \mathrm{O}_{3}$. The adiabatic flame temperature decreases with the increase of $x$. First, seven sets of raw materials were prepared by balancing the molar ratios with $\mathrm{x}$ ranging from 1.5 to $1.9 . \mathrm{BaF}_{2}(99.9 \%$ purity), $\mathrm{NaF}$ ( $\geq 99.9 \%$ purity), and $\mathrm{CaF}_{2}(99.9 \%$ purity) were used as fluxes, at ratios of 0-7 wt \%, 0-5 wt\%, and 0-5 wt\%, respectively. $\mathrm{Y}_{2} \mathrm{O}_{3}-\mathrm{CeO}_{2}$ as a coprecipitated material with a Ce concentration of 5 at\% (Nippon Yttrium Co., Ltd.) was also used as raw material.

The raw powders were mixed well in a rolling ball mill at a rate of 100 rpm for $4 \mathrm{~h}$. The mixed raw powders were then placed in graphite crucibles (120 $\mathrm{mm} \times 40 \mathrm{~mm} \times 40 \mathrm{~mm})$, which were ignited and combusted in an Ar-filled reactor, as shown in Fig. 1. The main components of the reactor are a stainless steel chamber, a control unit, and a gas control system. Before ignition, the reactor was evacuated using a rotary pump, and Ar gas was supplied to maintain atmospheric pressure. A disposable carbon foil was placed in contact with one 
end of the reactant, which was then electrically ignited using a voltage of $50 \mathrm{~V}$ and a current of $100 \mathrm{~A}$ at room temperature. After ignition, the exhaust valve was opened for 15 min until the product cooled down. The collected products were crushed and washed with distilled water to remove any soluble impurities (mainly $\mathrm{NaCl}$ ).

The product phases were analyzed using X-ray diffraction (XRD, Miniflex600, Rigaku) with $\mathrm{Cu} \mathrm{K}_{\alpha}$ radiation $(\lambda=1.54056 \mathrm{~nm})$. The photoluminescence properties were recorded using a spectrofluorometer (FP-6200, JASCO) at room temperature with an excitation wavelength of 460 $\mathrm{nm}$. The internal quantum efficiency was quantitatively determined using a fluorescence spectrometer (FP-8500, JASCO) equipped with an integrating sphere (ISF+834, JASCO). For cross-sectional elemental analysis of the particles, the obtained particles of $0.1 \mathrm{~g}$ were mixed with $2 \mathrm{~g}$ fine copper powder, and then hot pressed for $1 \mathrm{~h}$ at $250{ }^{\circ} \mathrm{C}$ to form a bulk sample, which was cut, polished, and ion milled using a cross-section polisher (IB-09010CP, JEOL). SEM-EDS (JSM-7001FA, JEOL) was used to confirm the elemental distribution. The valance of Ce ions in the synthesized phosphor was analyzed using XPS (JPS-9200, JEOL). 

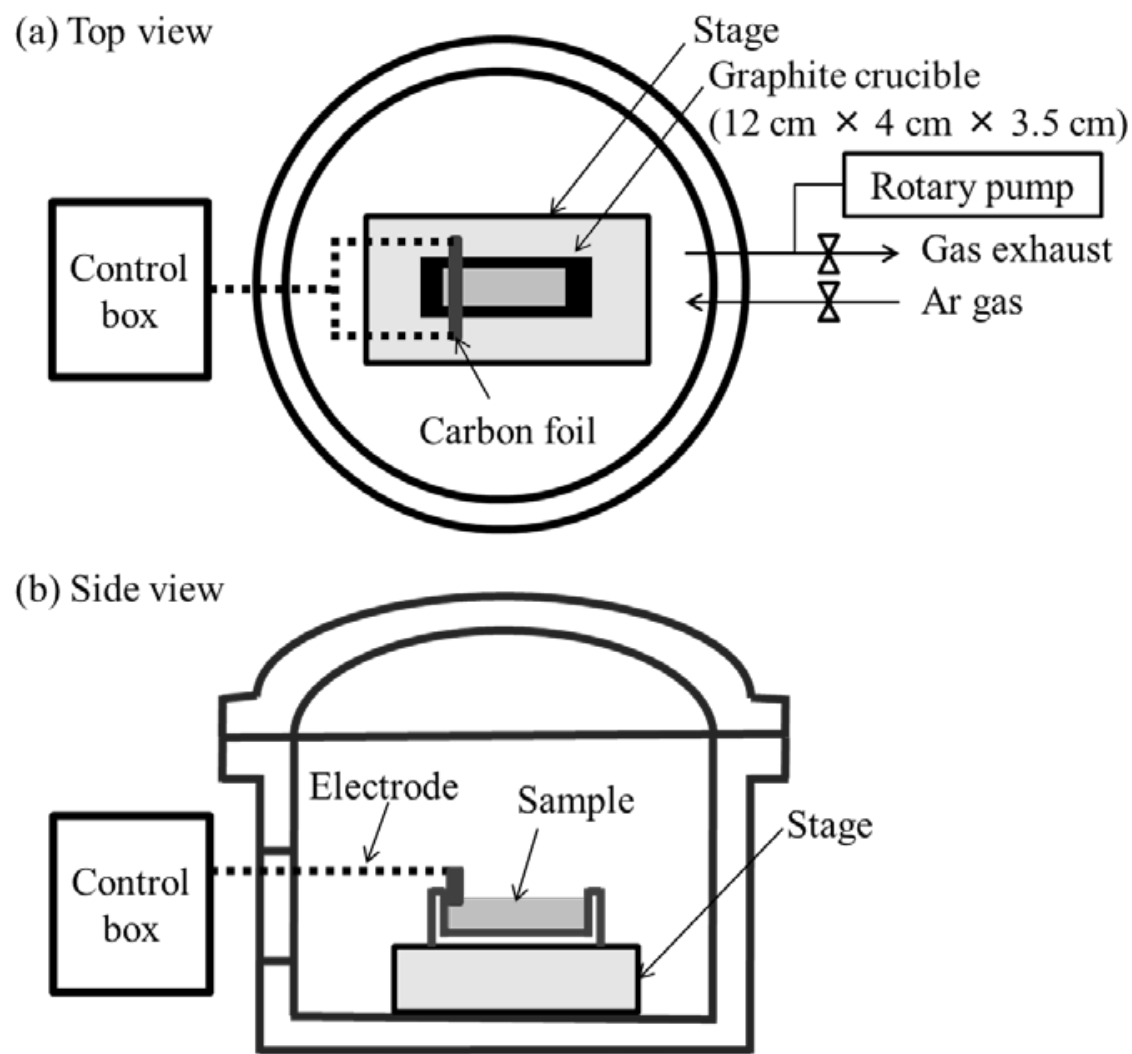

Fig. 1 Schematic diagram of the experimental apparatus for preparing samples by combustion synthesis. 


\section{Results and discussion}

\subsection{Effect of $\mathrm{Al}_{2} \mathrm{O}_{3}$ ratio in raw materials}

In this work, the combustion synthesis of YAG:Ce was promoted by the oxidation of $\mathrm{Al}$ by $\mathrm{O}_{2}$, which was released from $\mathrm{NaClO}_{4}$. The reaction temperature for the oxidation of $\mathrm{Al}$ can be in excess of $5300^{\circ} \mathrm{C}$, which can cause melting and extreme sintering of the products. Therefore, we added $\mathrm{Al}_{2} \mathrm{O}_{3}$ as a diluent, and studied the optimum amount $\mathrm{x}$ of $\mathrm{Al}_{2} \mathrm{O}_{3}$. Figure 2 shows photographs of samples obtained by combustion synthesis at different $\mathrm{x}$ values, as indicated in Eq. 1. The raw materials were in the form of gray powders. The combustion synthesis afforded yellow porous bulk materials with precipitated white powders of $\mathrm{NaCl}$. The raw materials were ignited from one end of the crucible. For samples with $\mathrm{x}=1.5-1.8$, yellow products were obtained throughout the crucible, which indicates that the raw materials were successfully ignited and the combustion reaction was propagated. However, excluding the ignition area, which showed a color change to yellow, the sample at $\mathrm{x}=1.9$ appeared the same as the raw material, indicating that combustion propagation failed owing to an excess amount of $\mathrm{Al}_{2} \mathrm{O}_{3}$ as a diluent. For samples with $\mathrm{x}=1.5-1.6$, the obtained yellow product seemed to be considerably melted, and a large amount of dark sintered agglomerates was obtained, which might be caused by a very high reaction temperature at higher $\mathrm{Al}$ ratios. For samples with $\mathrm{x}=1.75-1.8$, gray powders remained on the surface of the products, especially for samples with higher x values, indicating unreacted materials. In contrast, the products obtained at $\mathrm{x}=1.7-1.725$ showed the cleanest yellow color, suggesting the best conditions for producing YAG:Ce. 


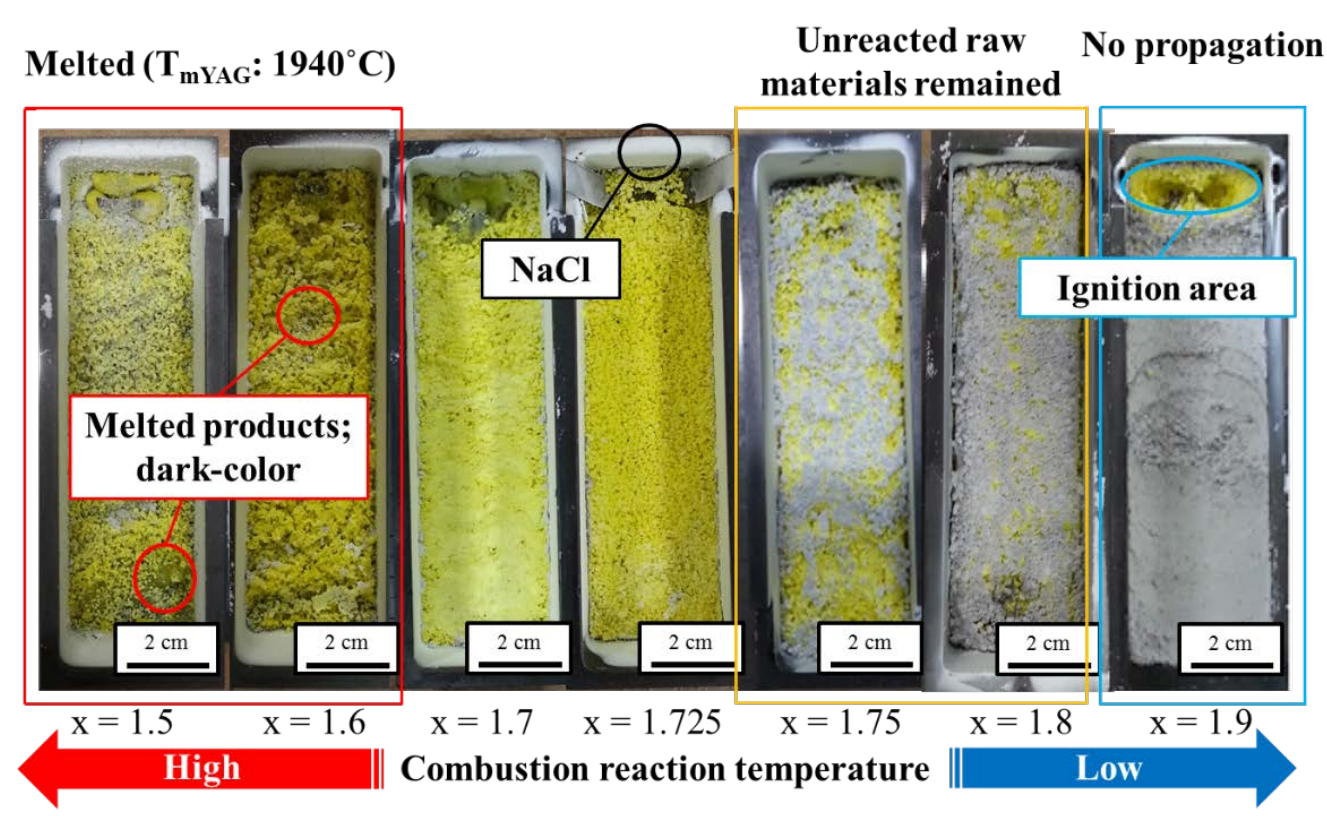

Fig. 2 Photographs of products after combustion synthesis at different $\mathrm{x}$ values.

Figure 3 shows XRD patterns of the products obtained at $\mathrm{x}=1.5-1.9$. For $\mathrm{x}=1.5$ and 1.6, the dark sintered agglomerates were removed from the XRD samples owing to difficulties in crushing these materials. The white product collected from the wall of the crucible and the product before washing are also shown for comparison. The XRD pattern of the white product was consistent with that of $\mathrm{NaCl}$, which could be removed by washing with water. The main phase of all products was YAG, and a small amount of the YAP $\left(\mathrm{YAlO}_{3}\right)$ phase was also detected at $\mathrm{x}=1.5-1.8$. Although the peak intensity of YAP was nearly unchanged at $x=1.5-1.725$, it gradually increased with $x$ in the range of $1.725-$ 1.8. The $\mathrm{Al}_{2} \mathrm{O}_{3}-\mathrm{Y}_{2} \mathrm{O}_{3}$ system has three phases: $\mathrm{Y}_{4} \mathrm{Al}_{2} \mathrm{O}_{9}$ (YAM), $\mathrm{YAlO}_{3}$ (YAP), and $\mathrm{Y}_{3} \mathrm{Al}_{5} \mathrm{O}_{12}$ (YAG). It is assumed that YAG is formed through the following three reactions[24]:

$$
2 \mathrm{Y}_{2} \mathrm{O}_{3}+\mathrm{Al}_{2} \mathrm{O}_{3} \rightarrow \mathrm{Y}_{4} \mathrm{Al}_{2} \mathrm{O}_{9}
$$




$$
\begin{aligned}
& \mathrm{Al}_{2} \mathrm{O}_{3}+\mathrm{Y}_{4} \mathrm{Al}_{2} \mathrm{O}_{9} \rightarrow 4 \mathrm{YAlO}_{3} \\
& 3 \mathrm{YAlO}_{3}+\mathrm{Al}_{2} \mathrm{O}_{3} \rightarrow \mathrm{Y}_{3} \mathrm{Al}_{5} \mathrm{O}_{12}
\end{aligned}
$$

If the heat treatment starts beneath a molar ratio for $\mathrm{Al}_{2} \mathrm{O}_{3}$ to $\mathrm{Y}_{2} \mathrm{O}_{3}$ of 5:3, a YAM phase is initially stabilized in the range from $1100^{\circ} \mathrm{C}$ to $1400^{\circ} \mathrm{C}$. Within the temperature range of $1200-1600^{\circ} \mathrm{C}$, a YAP phase forms, and YAG is produced over $1300^{\circ} \mathrm{C}$. Therefore, a heat treatment of over $1600^{\circ} \mathrm{C}$ is required to produce a pure YAG phase without YAP formation[25]. YAP is known to form as a byproduct during solid-state reactions under insufficient heat treatment temperature or time[24]. In the case of our study, increased amount of $\mathrm{Al}_{2} \mathrm{O}_{3}(\mathrm{x})$ decreased the reaction temperature, resulting the increased YAP formation with $\mathrm{x}$ in the range of 1.725-1.8. 


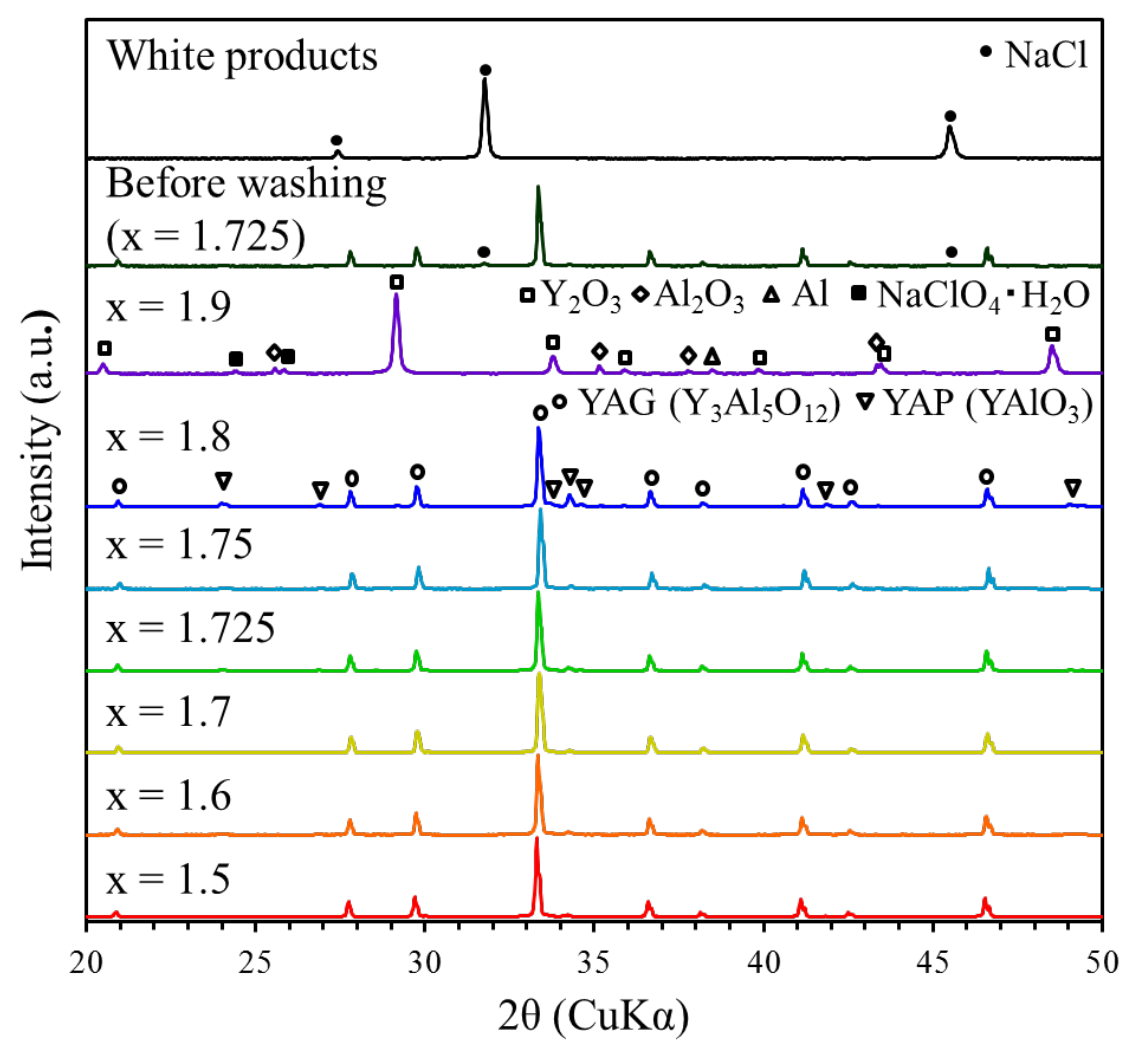

Fig. 3 XRD patterns of the products after combustion synthesis at different $\mathrm{x}$ values. The white product collected from the wall of the crucible and the product before washing with water are also shown for comparison.

Figure 4 shows the luminescence spectra $\left(\lambda_{\mathrm{ex}}=460 \mathrm{~nm}\right)$ of the YAG:Ce samples with $\mathrm{x}=1.50-1.80$. The samples exhibited broad emission peaks in the range of $470-700 \mathrm{~nm}$. This characteristic peak is attributed to the $\mathrm{Ce}^{3+} 5 d \rightarrow 4 f$ intershell transition[26], and the luminescence spectra are similar to those of YAG:Ce samples in other studies[26, 27]. The emission intensity increased with $\mathrm{x}$ in the range of $1.5-1.725$, and the intensity was almost constant for $\mathrm{x}=1.7-$ 1.75. In particular, the highest emission intensity was measured at $x=1.725$. However, the emission intensity significantly decreased at $x=1.8$ because of the 
increase of unreacted materials and the decreased heat for crystal growth. The maximum emission peak wavelengths and intensities are shown in the inset of Fig. 4. The peak wavelengths ranged from 527 to $531 \mathrm{~nm}$, with a gradual shift to longer wavelengths for $\mathrm{x}=1.5-1.725$, and a shift to shorter wavelengths for $\mathrm{x}=$ 1.75-1.8. Generally, luminescence spectra are red-shifted at higher $\mathrm{Ce}^{3+}$ concentrations [10, 27]. Therefore, these results indicate that the concentration of $\mathrm{Ce}^{3+}$ in the YAG matrix increased for $\mathrm{x}=1.5-1.725$ and decreased for $\mathrm{x}=1.75-$ 1.8. From the above results, it is concluded that $x=1.725-1.75$ is the optimum condition for introducing Ce into the YAG matrix as $\mathrm{Ce}^{3+}$.

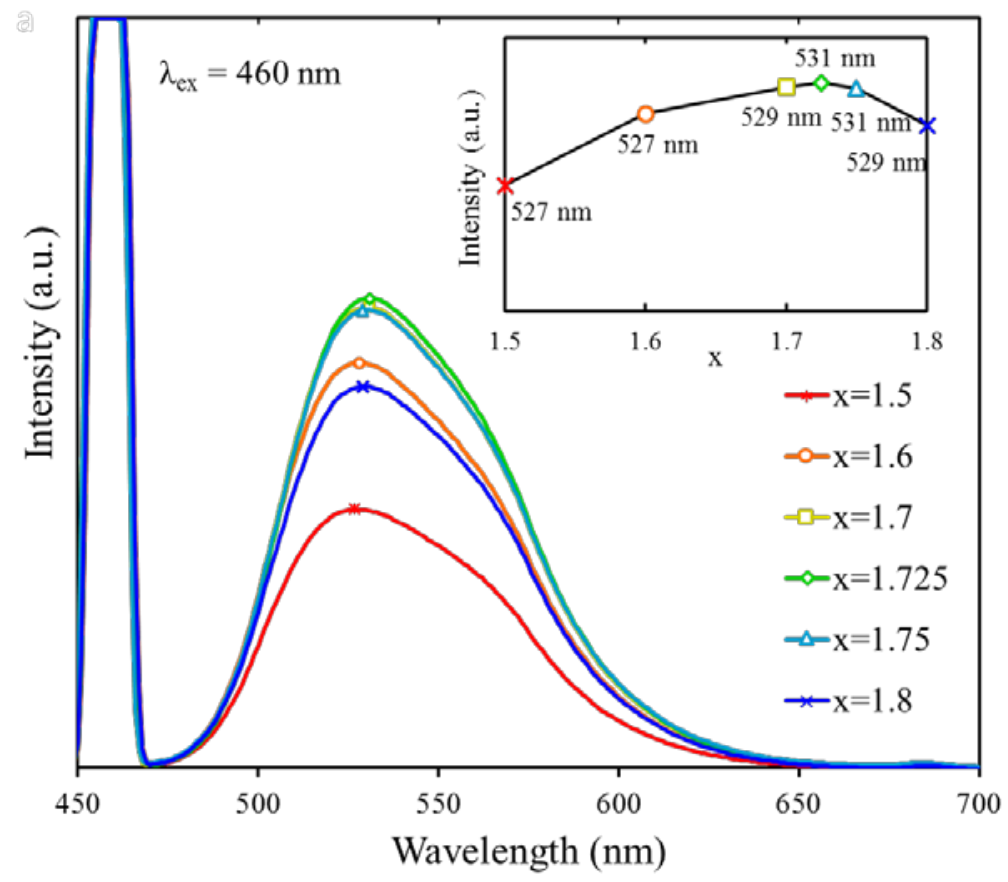

Fig. 4 Emission spectra $\left(\lambda_{\mathrm{ex}}=460 \mathrm{~nm}\right)$ for the combustion-synthesized products with different $\mathrm{x}$ values. The inset shows the maximum intensity of the luminescence spectra at different $\mathrm{x}$ values and the corresponding peak wavelengths. 



\subsection{Effect of fluxes}

To improve the luminescence properties, the addition of flux $\left(\mathrm{BaF}_{2}, \mathrm{NaF}\right.$, or $\mathrm{CaF}_{2}$ ) at different ratios during combustion synthesis was investigated. The amount of $\mathrm{Al}_{2} \mathrm{O}_{3}$ (x) was fixed as 1.725 based on the results in section 3.1. Under all experimental conditions, the combustion reaction occurred and final products were obtained without unreacted materials. When the produced materials were observed under ultraviolet light, the sample obtained using $\mathrm{BaF}_{2}$ showed stronger yellow emission than those obtained with $\mathrm{NaF}$ and $\mathrm{CaF}_{2}$. Figure 5 shows the XRD pattern of the products synthesized with different amounts of $\mathrm{BaF}_{2}$. Each sample consisted mainly of the YAG phase, but small amounts of the YAP phase are also observed. Temperature-time profile for combustion synthesis of YAG:Ce with 5 wt $\% \mathrm{BaF}_{2}$ was recorded, where the combustion temperature exceeded $1400{ }^{\circ} \mathrm{C}$. As we discussed above, YAG is produced over $1300^{\circ} \mathrm{C}$. However, the reaction time of combustion synthesis is still short. In addition, the temperature distribution also exists into the crucible, in which the temperature at center is relatively high compared to surface. By such reasons, small amount of YAP phase was still present. Further, the amount of residual $\mathrm{BaF}_{2}$ increased as the amount of $\mathrm{BaF}_{2}$ added increased. The XRD patterns of the sample obtained using $\mathrm{NaF}$ and $\mathrm{CaF}_{2}$ are obtained, in which the YAG phase and small amounts of the YAP phase are detected. Peaks originating from the fluxes are not observed. The luminescence properties of the sample with added $\mathrm{BaF}_{2}$ were examined, as shown in Fig. 6. $\mathrm{BaF}_{2}$ addition increased the luminescence properties, with a maximum emission intensity achieved at $5 \mathrm{wt} \%$, but addition of $6-7 \mathrm{wt} \% \mathrm{BaF}_{2}$ decreased the emission intensity owing to residual $\mathrm{BaF}_{2}$ after combustion. The 
luminescence properties of the $\mathrm{NaF}$ and $\mathrm{CaF}_{2}$ samples were measured, in which similar yellow emission was observed, but these fluxes, especially $\mathrm{CaF}_{2}$, significantly decreased the luminescence properties compared with those with no added flux. From these results, we conclude that the addition of $5 \mathrm{wt} \% \mathrm{BaF}_{2}$ is the optimum condition for achieving higher luminescence intensity.

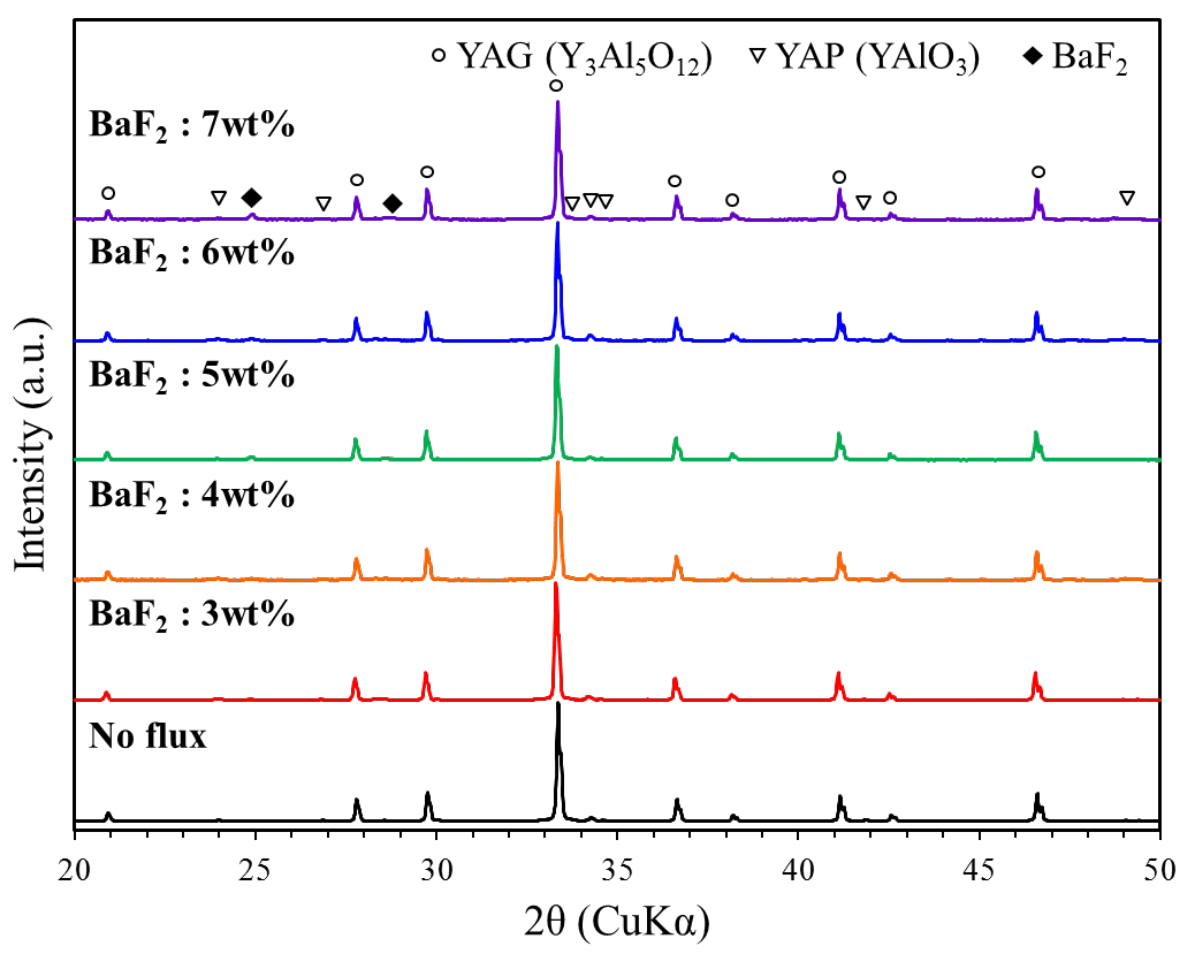

Fig. 5 XRD patterns of the products after combustion synthesis with different amounts of $\mathrm{BaF}_{2}$. 


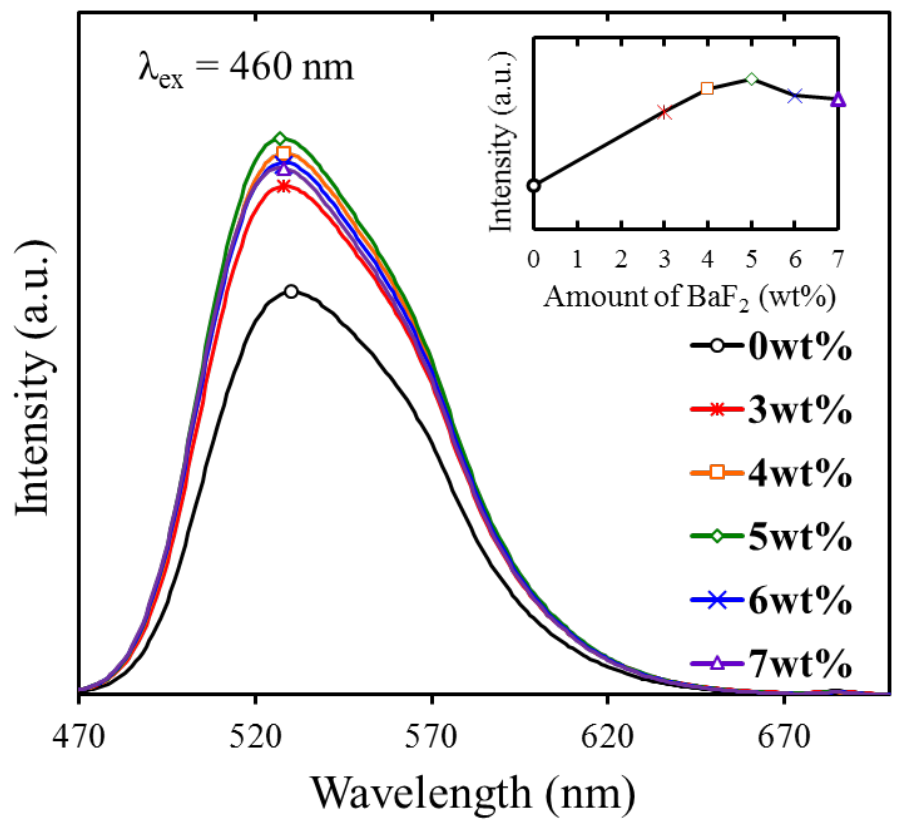

Fig. 6 Emission spectra $\left(\lambda_{\mathrm{ex}}=460 \mathrm{~nm}\right)$ for the combustion-synthesized products with different amounts of flux. The inset shows the relationships between amount of $\mathrm{BaF}_{2}$ and emission intensity at $528 \mathrm{~nm}$.

To investigate the role of $\mathrm{BaF}_{2}$ flux, the synthesized powders were characterized by SEM and EDS. Figure 7 shows SEM images of the particle surface and the corresponding elemental mappings. The SEM images reveal that the sample with no flux and that with $\mathrm{BaF}_{2}$ both have smooth surfaces. Elemental mapping from EDS also suggests a uniform distribution of $\mathrm{Al}$ and $\mathrm{Y}$, with $\mathrm{Ba}$ located at the interface between two particles (Fig. 7(d)). Subsequently, we prepared cross-sectional samples of the particles using mechanical and ion milling. Figure 8 shows compositional images of the cross-sections of the sample with no flux addition and that with $5 \mathrm{wt} \% \mathrm{BaF}_{2}$. In the sample with no flux (Fig. 8(a)), three phases with different contrasts are observed, namely, a dark gray matrix, light gray areas, and bright dots. In principle, for compositional images 
using backscattered electrons, the image contrast depends on the atomic number. Because YAG:Ce is composed of Y (39), $\mathrm{Al}$ (13), and Ce (58), the brightness of the constituent elements is predicted to be in the order of $\mathrm{Ce}>\mathrm{Y}>\mathrm{Al}$ in the compositional images. Therefore, the bright dots in Fig. 8(a) correspond to segregated Ce, the light gray areas are a Y-rich phase, and the dark gray matrix is an Al-rich phase. The elemental mapping shown in Fig. 8(b) agrees with this elemental distribution. The Y:Al ratios in YAP and YAG are 1:3 and 3:5, respectively. Therefore, the light gray Y-rich phase is YAP, and the dark gray matrix is YAG. In contrast to no flux addition, the utilization of $\mathrm{BaF}_{2}$ flux suppressed segregation and the elemental uniformity was improved. Although the YAP phase was still present in the $\mathrm{BaF}_{2}$ sample, as observed by XRD, the improved elemental uniformity effectively increased the luminescence properties.

Table 1 shows the chemical composition of the samples synthesized with and without $\mathrm{BaF}_{2}$, as obtained by analyzing 30 points in the dark gray matrix by SEM-EDS. The chemical composition is consistent with the YAG phase, and there is no difference between the sample with no flux added and that with $5 \mathrm{wt} \%$ $\mathrm{BaF}_{2}$. However, as shown in Fig. 8(d), in the sample with $5 \mathrm{wt} \% \mathrm{BaF}_{2}$, segregation of $\mathrm{Ba}$ is observed along the interface of particles, which suggests that elemental uniformity is improved by utilizing $\mathrm{BaF}_{2}$ flux. 

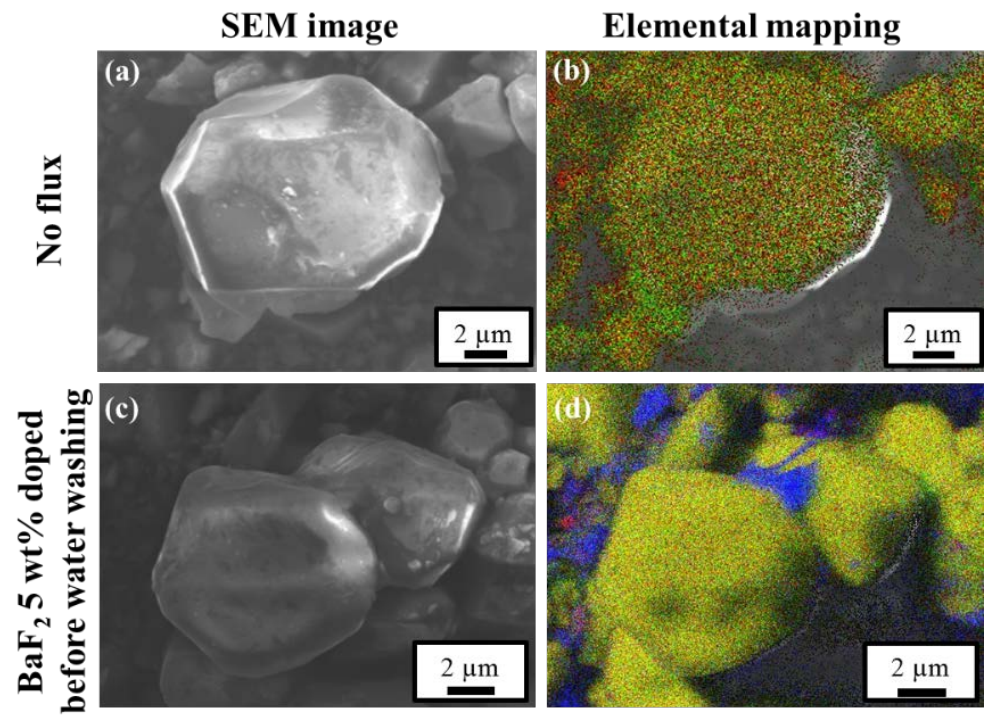

च: $\mathrm{Al} \quad \mathrm{Y} \quad \mathbf{\mathrm { Ba }}$

Fig. 7 SEM images and elemental mappings of the products synthesized with (a,b) no flux and (c,d) $5 \mathrm{wt} \% \mathrm{BaF}_{2}$.

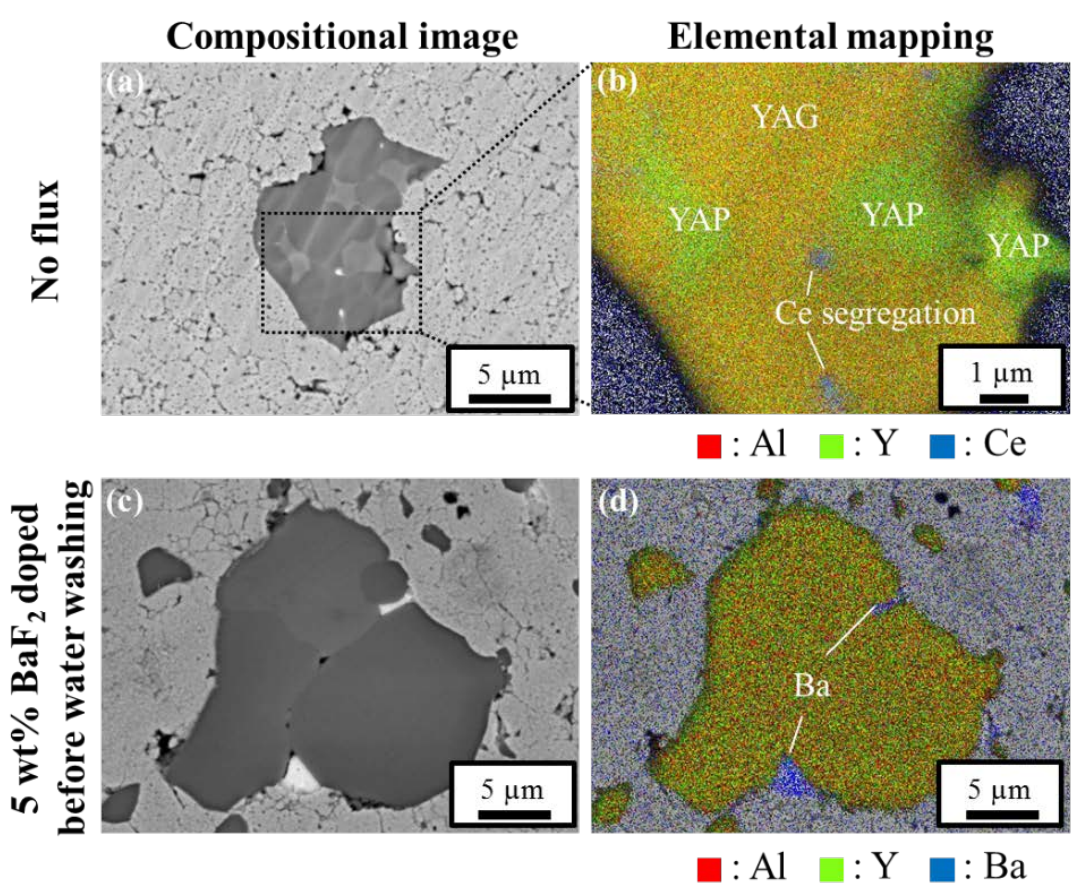

Fig. $8(\mathrm{a}, \mathrm{c})$ Compositional images of the cross-sections of samples without flux 
and with $5 \mathrm{wt} \% \mathrm{BaF}_{2}$. (b,d) Corresponding EDS mappings.

Table 1 Composition of YAG:Ce synthesized with and without $\mathrm{BaF}_{2}$, as measured by SEM-EDS point analysis.

\begin{tabular}{lllll}
\hline & O (at\%) & Al (at\%) & Y (at\%) & Ce (at\%) \\
\hline No flux & 56.38 & 23.21 & 20.35 & 0.042 \\
5 wt\% BaF 2 & 53.76 & 24.59 & 21.58 & 0.054 \\
\hline
\end{tabular}

A mechanism by $\mathrm{BaF}_{2}$ doping can affect YAG particle formation is proposed in Fig. 9. After ignition of the carbon foil, the combustion of $\mathrm{Al}$ with oxygen from $\mathrm{NaClO}_{4}$ proceeds, and the temperature rapidly increases (Fig. 9(a)). According to Capper et al., $\mathrm{Y}_{2} \mathrm{O}_{3}$ and $\mathrm{Al}_{2} \mathrm{O}_{3}$ can dissolve in molten $\mathrm{BaF}_{2}$ at high temperature[20]. When the sample temperature exceeds the melting point of $\mathrm{BaF}_{2}\left(1353^{\circ} \mathrm{C}\right.$ ), liquid $\mathrm{BaF}_{2}$ can cover the surfaces of $\mathrm{Y}_{2} \mathrm{O}_{3}$ and $\mathrm{Al}_{2} \mathrm{O}_{3}$ (Fig. 9(b)). According to the time profile of the reaction temperature, the combustion temperature does exceed the boiling point of $\mathrm{BaF}_{2}$. Ohno et al. also reported a decrease of the melting point for mixtures of $\mathrm{BaF}_{2}$ and $\mathrm{Y}_{2} \mathrm{O}_{3}$ owing to $\mathrm{YF}_{3}$ formation[28]. The phase diagram of $\mathrm{BaF}_{2}$ and $\mathrm{YF}_{3}$ clearly reveals that the melting point of this mixture is decreased to below $950{ }^{\circ} \mathrm{C}[29]$. Owing to this decreased melting point, it was predicted that the liquid phase of YAG and flux would be stable around $1000{ }^{\circ} \mathrm{C}$, as shown in Fig. 9(c). During the temperature decrease after the combustion reaction, the solid YAG phase precipitates from the 
uniform liquid phase (Fig. 9(d)) and grows into large particles (Fig. 9(e)). After solidification is completed, $\mathrm{BaF}_{2}$ remains at the interface of the grains, as observed in Fig. 7(d) and Fig. 8(d). In summary, the enhanced liquid phase stability that is achieved by utilizing $\mathrm{BaF}_{2}$ flux effectively increases the elemental uniformity of the final products.

(a)

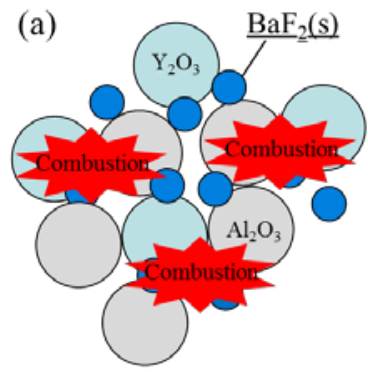

(d)

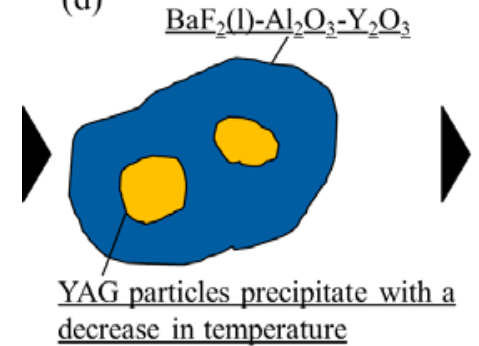

(b)

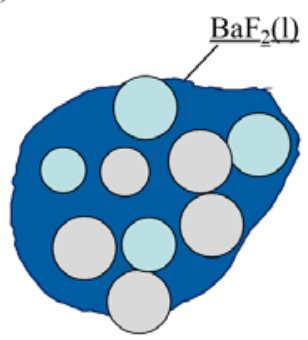

(e)

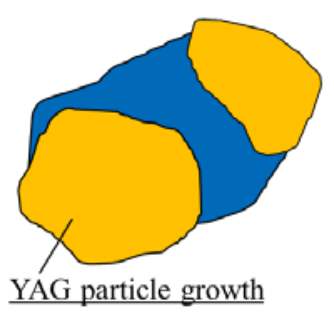

(c)

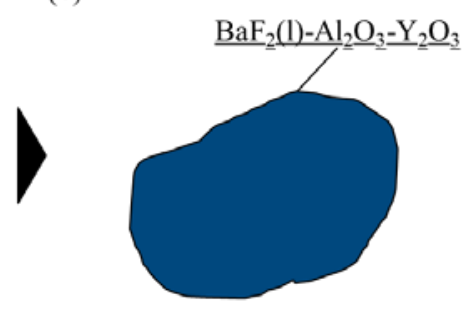

(f)

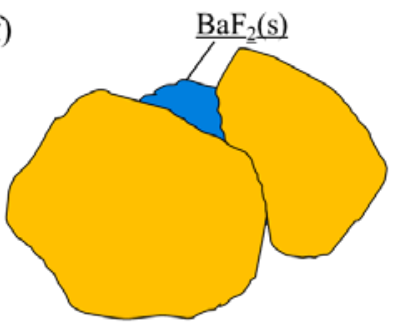

Fig. 9 Proposed mechanism by which $\mathrm{BaF}_{2}$ doping affects YAG particle formation. 


\subsection{Effect of coprecipitated material}

In addition to $\mathrm{BaF}_{2}$ flux, we also evaluated the effect of using a coprecipitated material of $\mathrm{Y}_{2} \mathrm{O}_{3}$ and $\mathrm{CeO}_{2}$. Because $\mathrm{Y}$ and Ce ions are uniformly distributed on the atomic scale in the coprecipitated material, segregation is expected to be suppressed. Figure 10 shows the XRD pattern of the powder synthesized using the coprecipitated material, in which the YAP phase is still generated. Figure 11 shows the emission spectrum and a photograph of the product. The sample with the coprecipitated material showed improved emission intensity of approximately $8.4 \%$ compared with the sample with only $\mathrm{BaF}_{2}$ added. The internal quantum efficiency (IQE) of the samples was also analyzed, as shown in Table 2. Similar to the change in emission intensity shown in Fig. 11, the IQE increased from $54.9 \%$ for the sample with no flux to $83.0 \%$ for the sample with flux and the coprecipitated material.

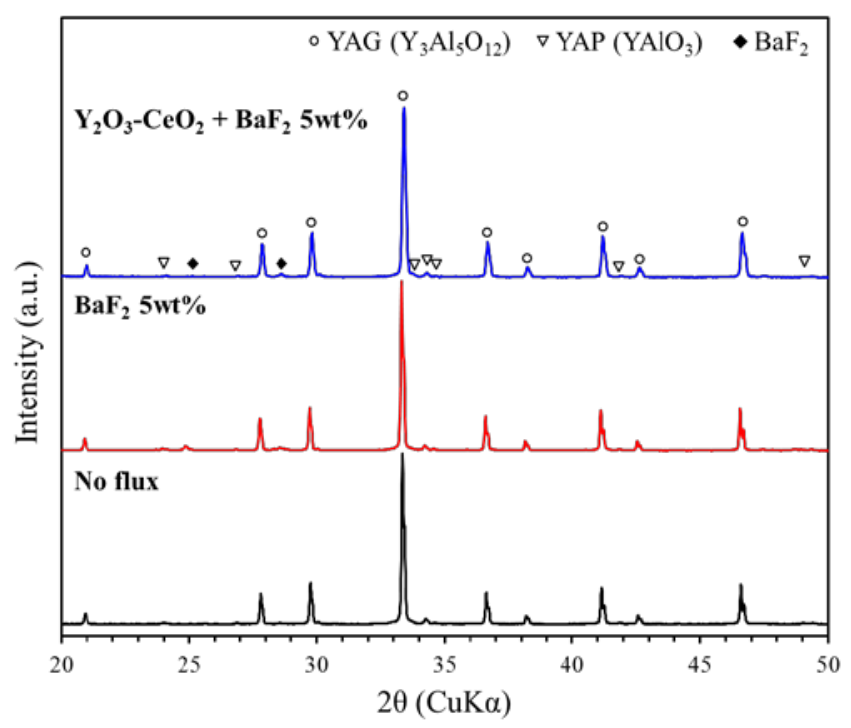

Fig. 10 XRD patterns of the products after combustion synthesis under different conditions: no flux, $5 \mathrm{wt} \% \mathrm{BaF}_{2}$, and $\mathrm{Y}_{2} \mathrm{O}_{3}-\mathrm{CeO}_{2}+5 \mathrm{wt} \% \mathrm{BaF}_{2}$. 


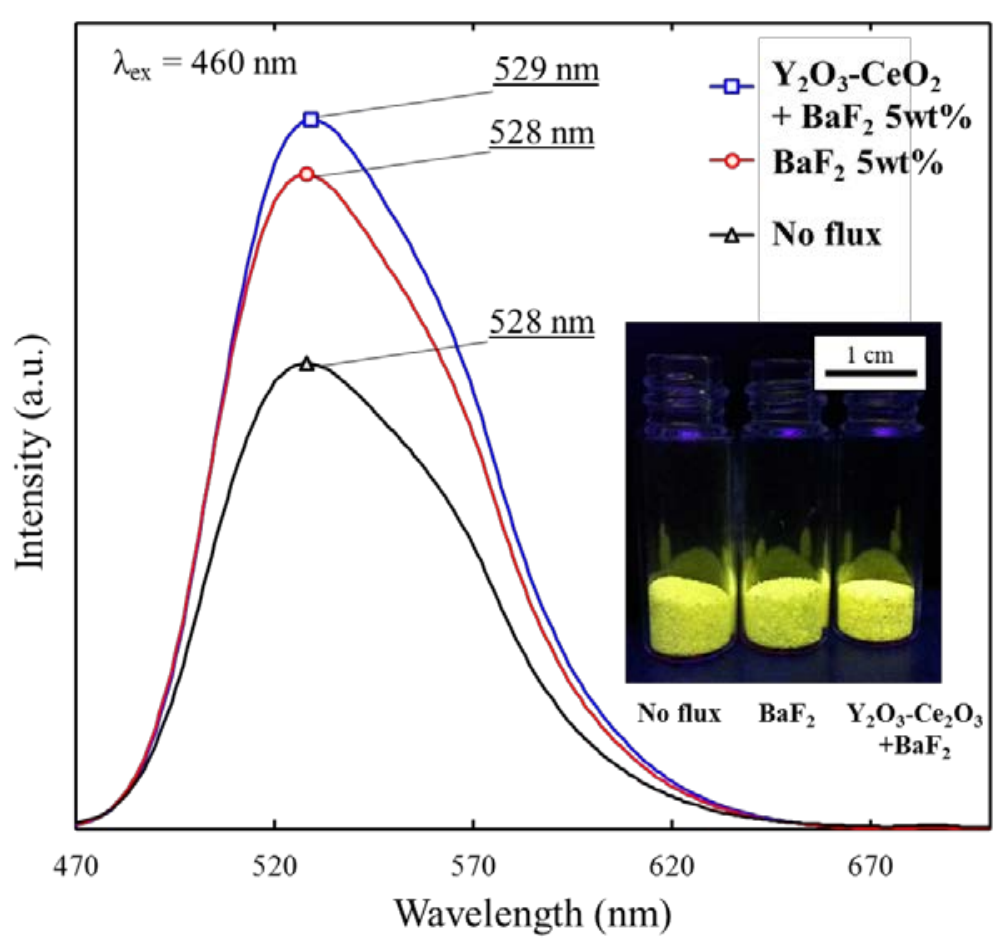

Fig. 11 Emission spectra $\left(\lambda_{\mathrm{ex}}=460 \mathrm{~nm}\right)$ for the combustion-synthesized products under different conditions: no flux, $5 \mathrm{wt} \% \mathrm{BaF}_{2}$, and $\mathrm{Y}_{2} \mathrm{O}_{3}-\mathrm{CeO}_{2}+5 \mathrm{wt} \% \mathrm{BaF}_{2}$. The inset shows a photograph of the synthesized powders under near-ultraviolet light.

Table 2 Internal quantum efficiency (IQE) of products synthesized under different conditions.

\begin{tabular}{ll}
\hline Sample & IQE (\%) \\
\hline $\mathrm{Y}_{2} \mathrm{O}_{3}-\mathrm{CeO}_{2}+5 \mathrm{wt} \% \mathrm{BaF}_{2}$ & 83.0 \\
$5 \mathrm{wt} \% \mathrm{BaF}_{2}$ & 73.2 \\
No flux & 54.9 \\
\hline
\end{tabular}


Figure 12 shows compositional images and corresponding EDS mappings of the cross-sections of the products synthesized with $5 \mathrm{wt} \% \mathrm{BaF}_{2}$ and $\mathrm{Y}_{2} \mathrm{O}_{3}-\mathrm{CeO}_{2}+5 \mathrm{wt} \% \mathrm{BaF}_{2}$. The distribution of $\mathrm{Al}$ and $\mathrm{Y}$ appears uniform in both samples, but segregation of $\mathrm{Ce}$ was only observed in the $\mathrm{BaF}_{2}$ sample. For smaller particles synthesized using $\mathrm{Y}_{2} \mathrm{O}_{3}-\mathrm{CeO}_{2}+5 \mathrm{wt} \% \mathrm{BaF}_{2}$, segregation of Ce disappeared. However, the larger particles still included segregated Ce. We also investigated the valance of Ce in the various samples using XPS. In the YAG structure, $\mathrm{Ce}$ is doped as $\mathrm{Ce}^{3+}$ ions. In contrast, segregated $\mathrm{CeO}_{2}$ contains $\mathrm{Ce}^{4+}$ ions. The ratio of $\mathrm{Ce}^{3+}$ and $\mathrm{Ce}^{4+}$ ions was determined from the shift in the binding energies in the Ce 3d XPS spectra (Fig. 13), in which four peaks $\left(\mathrm{Ce}^{4+} 3 \mathrm{~d}_{5 / 2}, \mathrm{Ce}^{4+}\right.$ $3 d_{3 / 2}, \mathrm{Ce}^{3+} 3 d_{5 / 2}$, and $\mathrm{Ce}^{3+} 3 \mathrm{~d}_{3 / 2}$ ) were separated using peak fitting[2, 30, 31]. From the peak fitting results, the peak positions, half-widths, and areas were determined, and the $\mathrm{Ce}^{3+} / \mathrm{Ce}^{4+}$ ratios were calculated, as shown in Tables 3 and 4 . Compared with the $\mathrm{BaF}_{2}$ sample, the $\mathrm{Ce}^{3+}$ ratio in the sample obtained using the coprecipitated material was $1.36 \%$ higher. These results indicate that the utilization of the coprecipitated material improves the luminescence properties by improving the uniformity of the sample. Because of the short reaction time during combustion synthesis, diffusion of each element might be insufficient, which causes segregation of Ce. 

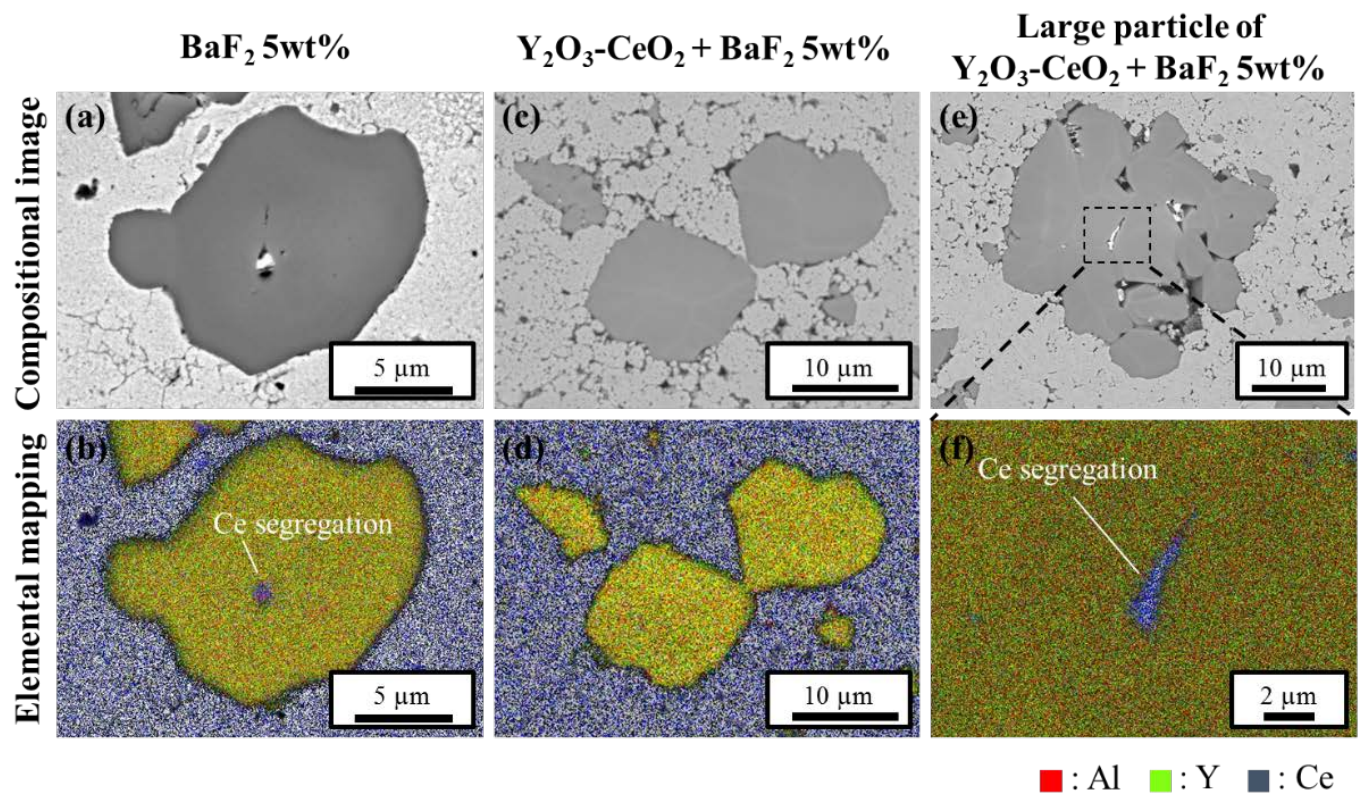

Fig. 12 Compositional images and corresponding EDS mappings of the cross-sections of the products synthesized using $5 \mathrm{wt} \% \mathrm{BaF}_{2}$ and $\mathrm{Y}_{2} \mathrm{O}_{3}-\mathrm{CeO}_{2}+5$ $\mathrm{wt} \% \mathrm{BaF}_{2}$.
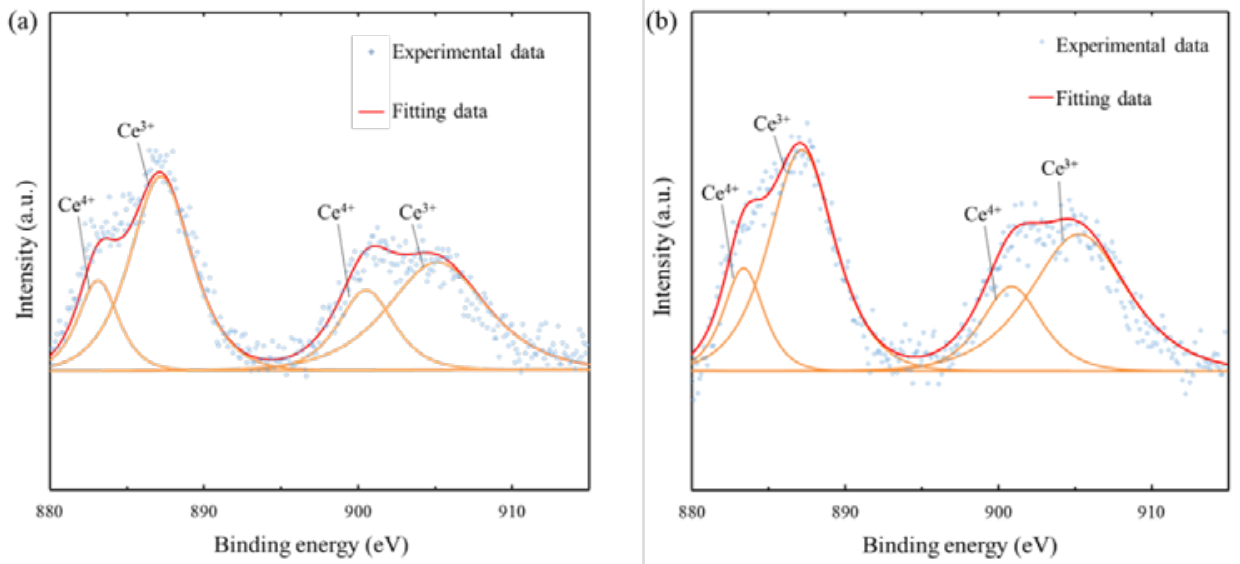

Fig. 13 Ce 3d XPS spectra of YAG:Ce powders synthesized with (a) $5 \mathrm{wt} \% \mathrm{BaF}_{2}$ and (a) $\mathrm{Y}_{2} \mathrm{O}_{3}-\mathrm{CeO}_{2}+5 \mathrm{wt} \% \mathrm{BaF}_{2}$. 
Table 3 XPS results and ratio of $\mathrm{Ce}^{3+}$ and $\mathrm{Ce}^{4+}$ in YAG:Ce synthesized with 5 $\mathrm{wt} \% \mathrm{BaF}_{2}$.

\begin{tabular}{lcccc}
\hline & $\mathrm{Ce}^{4+} 3 \mathrm{~d}_{5 / 2}$ & $\mathrm{Ce}^{4+} 3 \mathrm{~d}_{3 / 2}$ & $\mathrm{Ce}^{3+} 3 \mathrm{~d}_{5 / 2}$ & $\mathrm{Ce}^{3+} 3 \mathrm{~d}_{3 / 2}$ \\
\hline Peak (eV) & 883 & 901 & 887 & 905 \\
Half-width & 1.5 & 2.1 & 2.4 & 3.8 \\
Area & 499 & 612 & 1660 & 1471 \\
Sum & 1111 & & 3131 & \\
Ratio (\%) & 26.2 & & 73.8 & \\
\hline
\end{tabular}

Table 4 XPS results and ratio of $\mathrm{Ce}^{3+}$ and $\mathrm{Ce}^{4+}$ in YAG:Ce synthesized with $\mathrm{Y}_{2} \mathrm{O}_{3}-\mathrm{CeO}_{2}+5 \mathrm{wt} \% \mathrm{BaF}_{2}$.

\begin{tabular}{lllll}
\hline & $\mathrm{Ce}^{4+} 3 \mathrm{~d}_{5 / 2}$ & $\mathrm{Ce}^{4+} 3 \mathrm{~d}_{3 / 2}$ & $\mathrm{Ce}^{3+} 3 \mathrm{~d}_{5 / 2}$ & $\mathrm{Ce}^{3+} 3 \mathrm{~d}_{3 / 2}$ \\
\hline Peak (eV) & 883 & 901 & 887 & 905 \\
Half-width & 1.5 & 2.3 & 2.5 & 3.7 \\
Area & 575 & 707 & 2029 & 1852 \\
Sum & 1281 & & 3881 & \\
Ratio (\%) & 24.8 & & 75.2 & \\
\hline
\end{tabular}




\subsection{Equilibrium theory for phosphor synthesis}

In the above sections, we reported the luminescence properties, particle morphologies, and elemental distributions of the combustion-synthesized products. In this section, we use equilibrium theory to discuss why YAG:Ce phosphors can be synthesized in a shorter time by combustion synthesis than by solid-state reaction.

First, focusing on the synthesis of the YAG matrix, the reaction formulas of the two methods can be expressed by Eq. 5 (combustion synthesis) and Eq. 6 (solid-state reaction).

$1.5 \mathrm{Y}_{2} \mathrm{O}_{3}+1.725 \mathrm{Al}_{2} \mathrm{O}_{3}+1.55 \mathrm{Al}+0.58125 \mathrm{NaClO}_{4} \rightarrow \mathrm{Y}_{3} \mathrm{Al}_{5} \mathrm{O}_{12}+0.58125 \mathrm{NaCl}$

$1.5 \mathrm{Y}_{2} \mathrm{O}_{3}+2.5 \mathrm{Al}_{2} \mathrm{O}_{3} \rightarrow \mathrm{Y}_{3} \mathrm{Al}_{5} \mathrm{O}_{12}$

Figure 14(a) shows the temperature dependence of the standard free energy $\left(\Delta G^{0}\right.$, calculated using HSC Chemistry version 8.0) for Eq. 5 and Eq. 6. The $\Delta G^{0}$ value for Eq. 5 is considerably lower than that for Eq. 6, indicating that Eq. 5 has a higher driving force and can progress more easily than the reaction in Eq. 6. Second, we examined the reduction of $\mathrm{CeO}_{2}$ to $\mathrm{Ce}_{2} \mathrm{O}_{3}$. It is important to reduce $\mathrm{Ce}^{4+}$ to $\mathrm{Ce}^{3+}$ for the formation of YAG:Ce phosphors with Ce doped in the Y site. In solid-state reactions, a reduction atmosphere is always needed, and the following reactions can be considered:

$$
2 \mathrm{CeO}_{2}+\mathrm{CO} \rightarrow \mathrm{Ce}_{2} \mathrm{O}_{3}+\mathrm{CO}_{2}
$$




$$
2 \mathrm{CeO}_{2}+\mathrm{H}_{2} \rightarrow \mathrm{Ce}_{2} \mathrm{O}_{3}+\mathrm{H}_{2} \mathrm{O}
$$

In combustion synthesis, a different reduction reaction can be considered:

$$
2 \mathrm{CeO}_{2}+(2 / 3) \mathrm{Al} \rightarrow \mathrm{Ce}_{2} \mathrm{O}_{3}+(1 / 3) \mathrm{Al}_{2} \mathrm{O}_{3}
$$



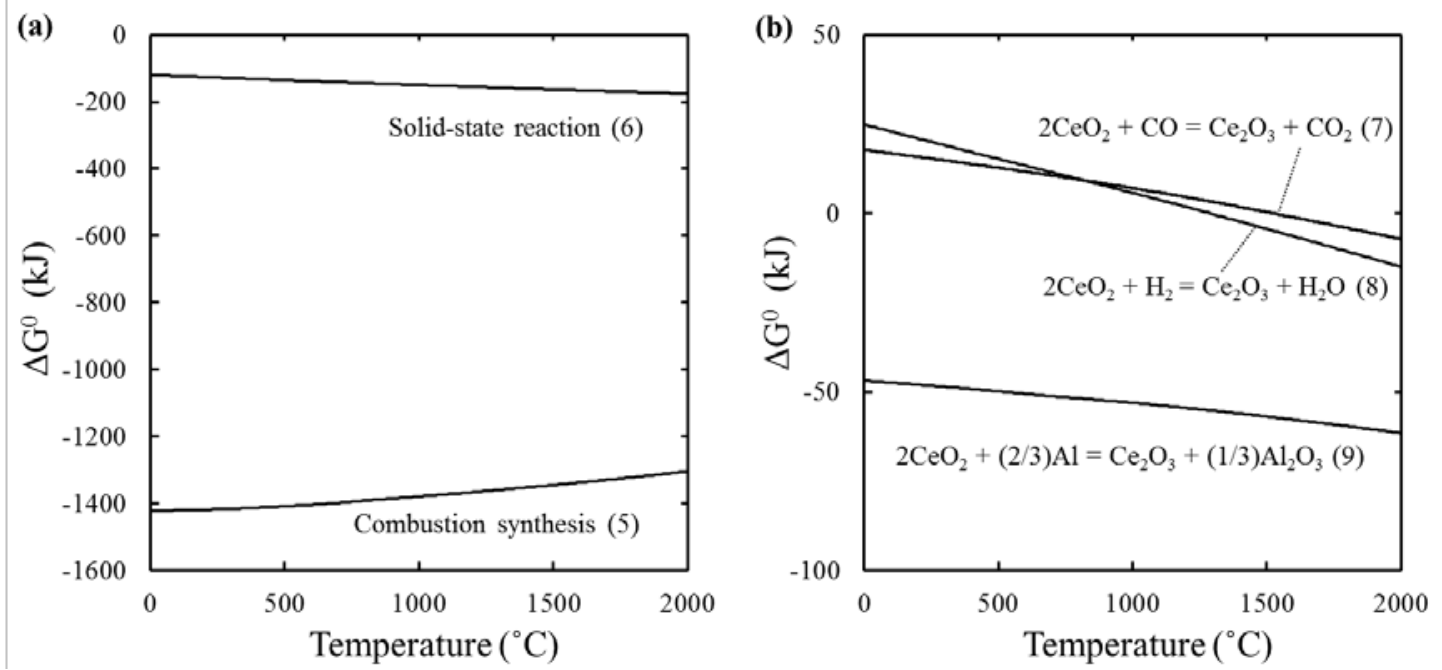

Fig. 14 (a) Temperature dependence of the standard free energy $\left(\Delta G^{0}\right)$ for the synthesis of YAG by combustion (Eq. 5) and solid-state reaction (Eq. 6). (b) Temperature dependence of $\Delta G^{0}$ for the reduction of $\mathrm{CeO}_{2}$ to $\mathrm{Ce}_{2} \mathrm{O}_{3}$ by $\mathrm{CO}$ (Eq. 7), $\mathrm{H}_{2}$ (Eq. 8), and $\mathrm{Al}$ (Eq. 9).

The $\Delta G^{0}$ values of these reactions as a function of temperature are shown in Fig. 14(b). To obtain a negative $\Delta G^{0}$ value, a temperature higher than $1530{ }^{\circ} \mathrm{C}$ is required for Eq. 7, whereas a temperature higher than $1290{ }^{\circ} \mathrm{C}$ is required for Eq. 8, which correspond to the lowest temperatures for the reduction of $\mathrm{Ce}^{4+}$ to $\mathrm{Ce}^{3+}$. However, interestingly, for Eq. 9, negative $\Delta G^{0}$ values are obtained over a wide temperature range, including room temperature, which indicates that combustion synthesis not only forms the YAG matrix, but also easily introduces $\mathrm{Ce}^{3+}$ as a dopant into the YAG matrix. For these reasons, YAG:Ce phosphors were successfully synthesized by combustion synthesis, which has obvious advantages, such as low energy consumption and short reaction times. 


\section{Conclusion}

YAG:Ce phosphors were successfully prepared by combustion synthesis via the thermite reaction of $\mathrm{Al}$. The reaction temperature was controlled by varying $\mathrm{x}$, the ratio of $\mathrm{Al}_{2} \mathrm{O}_{3}$ to $\mathrm{Al}$. The combustion reaction proceeded at $\mathrm{x} \leq 1.8$, and $\mathrm{x}=1.725$ was the optimum condition for producing a high-performance product. When $5 \mathrm{wt} \% \mathrm{BaF}_{2}$ was added, the luminescence intensity was significantly improved owing to decreased YAP formation with improved elemental uniformity through the effect of the flux on the liquid phase. We also evaluated the effect of a coprecipitated material of $\mathrm{Y}_{2} \mathrm{O}_{3}$ and $\mathrm{CeO}_{2}$. The combination of $\mathrm{BaF}_{2}$ and the coprecipitated material significantly improved the IQE to $83.0 \%$, which is close to that of commercial phosphors. Equilibrium theory indicates that combustion synthesis not only forms the YAG matrix, but also introduces $\mathrm{Ce}^{3+}$ into the YAG matrix more easily than in a solid-state reaction. These results demonstrate the potential of this facile combustion synthesis method for synthesizing high-performance phosphors via the thermite reaction of $\mathrm{Al}$ in a short time by utilizing flux and coprecipitated raw materials. 


\section{Acknowledgements}

Part of this work was conducted at the Laboratory of XPS analysis, Hokkaido University, supported by the "Nanotechnology Platform" Program of the Ministry of Education, Culture, Sports, Science and Technology of Japan (MEXT). We gratefully acknowledge Mr. K. Suzuki, Mr. K. Ohkubo, Mr. R. Oota, Mr. T. Tanioka, Ms. Y. Yamanouchi, and Ms. E. Obari for their technical support in SEM experiments. We also thank Mr. K. Harada (Combustion Synthesis Co., Ltd.) for assistance. The measurements of internal quantum efficiency were supported by JASCO. 


\section{References}

[1] Lee Sang Ho, Jung Dae Soo, Han Jin Man, Young Koo Hye, Kang Yun Chan. Fine-sized $\mathrm{Y}_{3} \mathrm{Al}_{5} \mathrm{O}_{12}$ :Ce phosphor powders prepared by spray pyrolysis from the spray solution with barium fluoride flux. J. Alloys Compd., 2009, 477(1-2): 776.

[2] Rosa E. De la, Díaz-Torres L. A., Salas P., Arredondo A., Montoya J. A., Angeles C., Rodríguez R. A. Low temperature synthesis and structural characterization of nanocrystalline YAG prepared by a modified sol-gel method. Opt. Mater., 2005, 27(12): 1793.

[3] Veith Michael, Mathur Sanjay, Kareiva Aivaras, Jilavi Mohammad, Zimmer Michael, Huch Volker. Low temperature synthesis of nanocrystalline $\mathrm{Y}_{3} \mathrm{Al}_{5} \mathrm{O}_{12}$ (YAG) and Ce-doped $\mathrm{Y}_{3} \mathrm{Al}_{5} \mathrm{O}_{12}$ via different sol-gel methods. J. Mater. Chem., 1999, 9(12): 3069.

[4] Sundarakannan B., Kottaisamy M. Sol-gel derived flux assisted synthesis of fine particles YAG: $\mathrm{Ce}^{3+}$ phosphor for remote phosphor converted white light emitting diodes. Mater. Res. Bull., 2016, 74: 485.

[5] Dai Peng, Ji Cheng, Shen Liming, Qian Qi, Guo Guobiao, Zhang Xiaoyan, Bao Ningzhong. Photoluminescence properties of YAG:Ce3+,Pr3+ nano-sized phosphors synthesized by a modified co-precipitation method. J. Rare Earths, 2017, 35(4): 341.

[6] Que Meidan, Que Wenxiu, Zhou Ting, Shao Jinyou, Kong Lingbing. Enhanced photoluminescence property of sulfate ions modified YAG:Ce3+ phosphor by co-precipitation method. J. Rare Earths, 2017, 35(3): 217.

[7] Zhang Le, Lu Zhou, Zhu Jinzhen, Yang Hao, Han Pengde, Chen Yan, Zhang Qitu. Citrate sol-gel combustion preparation and photoluminescence properties of YAG:Ce phosphors. J. Rare Earths, 2012, 30(4): 289.

[8] Gupta K. V. K., Muley A., Yadav P., Joshi C. P., Moharil S. V. Combustion synthesis of YAG:Ce and related phosphors. Appl. Phys. B., 2011, 105(2): 479.

[9] Yang Zhiping, Li Xu, Yang Yong, Li Xingmin. The influence of different conditions on the luminescent properties of YAG:Ce phosphor formed by combustion. J. Lumin., 2007, 122-123: 707.

[10] Xia Guodong, Zhou Shengming, Zhang Junji, Xu Jun. Structural and optical properties of YAG: $\mathrm{Ce}^{3+}$ phosphors by sol-gel combustion method. J. Cryst. Growth., 2005, 279(3-4): 357.

[11] Yang Huijuan, Yuan Le, Zhu Guisheng, Yu Aibing, Xu Huarui. Luminescent properties of YAG: $\mathrm{Ce}^{3+}$ phosphor powders prepared by hydrothermal-homogeneous precipitation method. Mater. Lett., 2009, 63(27): 2271.

[12] Kitamura Yasuaki, Okinaka Noriyuki, Shibayama Tamaki, Mahaney Orlando Omar 
Prieto, Kusano Daisuke, Ohtani Bunsho, Akiyama Tomohiro. Combustion synthesis of TiO2 nanoparticles as photocatalyst. Powder Technol., 2007, 176(2-3): 93.

[13] Nobuta Akira, Hsieh Feng-Fan, Shin Tae Ho, Hosokai Sou, Yamamoto Satoshi, Okinaka Noriyuki, Ishihara Tatsumi, Akiyama Tomohiro. Self-propagating high-temperature synthesis of $\mathrm{La}(\mathrm{Sr}) \mathrm{Ga}(\mathrm{Mg}, \mathrm{Fe}) \mathrm{O}_{3-8}$ with planetary ball-mill treatment for solid oxide fuel cell electrolytes. J. Alloys Compd., 2011, 509(33): 8387.

[14] Hiramoto Maki, Okinaka Noriyuki, Akiyama Tomohiro. Self-propagating high-temperature synthesis of nonstoichiometric wüstite. J. Alloys Compd., 2012, 520: 59 .

[15] Saito Genki, Niu Jing, Yi Xuemei, Kunisada Yuji, Sakaguchi Norihito, Akiyama Tomohiro. Salt-assisted combustion synthesis of $\mathrm{Ca}^{-\alpha}-\mathrm{SiAlON}: \mathrm{Eu}^{2+}$ phosphors. $J$. Alloys Compd., 2016, 681: 22.

[16] Niu Jing, Saito Genki, Akiyama Tomohiro. A New Route to Synthesize B-SiAlON:Eu ${ }^{2+}$ Phosphors for White Light-Emitting Diodes. Appl. Phys. Express, 2013, 6(4): 042105.

[17] Ge Yiyao, Tian Zhaobo, Chen Ying, Sun Siyuan, Zhang Jie, Xie Zhipeng. Effect of comburent ratios on combustion synthesis of Eu-doped B-SiAlON green phosphors. $J$. Rare Earths, 2017, 35(5): 430.

[18] Deguchi Masaya, Yasuda Naoto, Zhu Chunyu, Okinaka Noriyuki, Akiyama Tomohiro. Combustion synthesis of TiFe by utilizing magnesiothermic reduction. J. Alloys Compd., 2015, 622: 102.

[19] Abe Keisuke, Kikuchi Asami, Okinaka Noriyuki, Akiyama Tomohiro. Single thermite-type combustion synthesis of $\mathrm{Fe}_{2} \mathrm{VAl}$ for thermoelectric applications from $\mathrm{Fe}, \mathrm{V}_{2} \mathrm{O}_{5}$ and $\mathrm{Al}$ powders. J. Alloys Compd., 2014, 611: 319.

[20] Xu Shiqing, Sun Liuzheng, Zhang Ying, Ju Haidong, Zhao Shilong, Deng Degang, Wang Huanping, Wang Baoling. Effect of fluxes on structure and luminescence properties of $\mathrm{Y}_{3} \mathrm{Al}_{5} \mathrm{O}_{12}: \mathrm{Ce}^{3+}$ phosphors. J. Rare Earths, 2009, 27(2): 327.

[21] Capper P., Elwell D. Appraisal of $\mathrm{BaO} / \mathrm{B}_{2} \mathrm{O}_{3} / \mathrm{BaF}_{2}$ fluxes for the growth of yttrium aluminium garnet. J. Cryst. Growth. 1974, 26(1): 65.

[22] Ye Linqin, Peng Xingping, Zhang Shuihe, Wang Yuhua, Chang Wenrui. Photoluminescence properties of Ca-doped BaMgAl10O17: $\mathrm{Eu}^{2+}, \mathrm{Mn}^{2+}$ blue phosphor using $\mathrm{BaF}_{2}$ and $\mathrm{CaF}_{2}$ as co-flux. J. Rare Earths, 2014, 32(12): 1109.

[23] Kanai Kazuaki, Fukui Yoshifumi, Kozawa Takahiro, Kondo Akira, Naito Makio. Effect of BaF2 powder addition on the synthesis of YAG phosphor by mechanical method. Adv. Powder Technol., 2017, 28(1): 50.

[24] Won C. W., Nersisyan H. H., Won H. I., Lee J. H., Lee K. H. Efficient solid-state route for 
the preparation of spherical YAG:Ce phosphor particles. J. Alloys Compd., 2011, 509(5): 2621.

[25] Ogi Takashi, Nandiyanto Asep Bayu Dani, Wang Wei-Ning, Iskandar Ferry, Okuyama Kikuo. Direct synthesis of spherical YAG:Ce phosphor from precursor solution containing polymer and urea. Chem. Eng. J., 2012, 210: 461.

[26] Purwanto Agus, Wang Wei-Ning, Ogi Takashi, Lenggoro I. Wuled, Tanabe Eishi, Okuyama Kikuo. High luminance YAG:Ce nanoparticles fabricated from urea added aqueous precursor by flame process. J. Alloys Compd., 2008, 463(1-2): 350.

[27] Bachmann Volker, Ronda Cees, Meijerink Andries. Temperature Quenching of Yellow $\mathrm{Ce}^{3+}$ Luminescence in YAG:Ce. Chem. Mater., 2009, 21(10): 2077.

[28] Ohno Katsutoshi, Abe Tomohiko. The Synthesis and Particle Growth Mechanism of Bright Green Phosphor YAG:Tb. J. Electrochem. Soc., 1994, 141(5): 1252.

[29] Nakamura G. H. G., Baldochi S. L., Mazzocchi V. L., Parente C. B. R., Valério M. E. G., Klimm D. Problems in the thermal investigation of the $\mathrm{BaF}_{2}-\mathrm{YF}_{3}$ system. J. Therm. Anal. Calorim., 2009, 95(1): 43.

[30] Wang Lianming, Zhuang Liqiang, Xin Hao, Huang Yuexia, Wang Deqiang. Semi-Quantitative Estimation of $\mathrm{Ce}^{3+} / \mathrm{Ce}^{4+}$ Ratio in YAG: $\mathrm{Ce}^{3+}$ Phosphor under Different Sintering Atmosphere. Open J. Inorg. Chem., 2015, 5(01): 12.

[31] Chao Wen-Hsuan, Wu Ren-Jye, Wu Tai-Bor. Structural and luminescent properties of YAG:Ce thin film phosphor. J. Alloys Compd., 2010, 506(1): 98. 


\section{Graphical abstract}

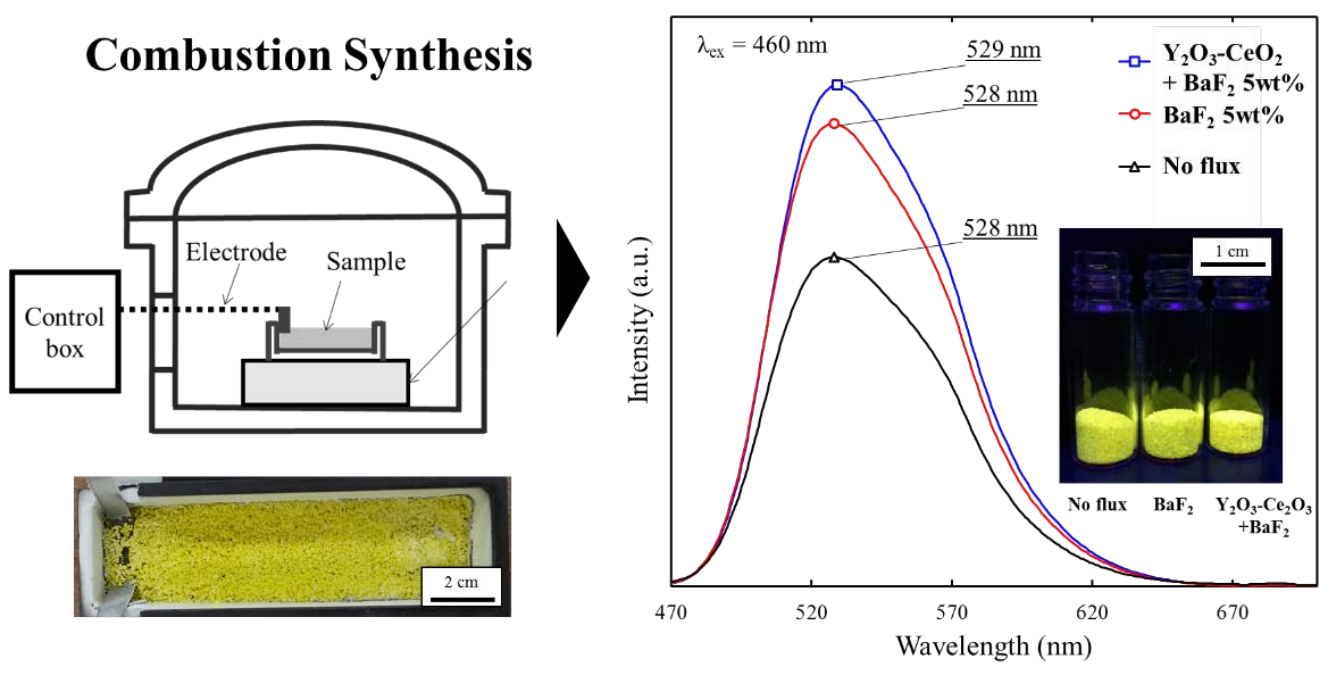

Schematic diagram of the experimental apparatus for combustion synthesis and Emission spectra for the combustion-synthesized products under different conditions: no flux, $5 \mathrm{wt} \% \mathrm{BaF}_{2}$, and $\mathrm{Y}_{2} \mathrm{O}_{3}-\mathrm{CeO}_{2}+5 \mathrm{wt} \% \mathrm{BaF}_{2}$. The inset shows a photograph of the synthesized powders. 